Research Article

\title{
Experimental Study on Adsorption Pore Structure and Gas Migration of Coal Reservoir Using Low-Field Nuclear Magnetic Resonance
}

\author{
Jiazhuo Li $\left(\mathbb{D},{ }^{1,2,3}\right.$ Penghui Guo, ${ }^{1}$ Wenhao Xie, ${ }^{1}$ Jiaqi Chu, ${ }^{1}$ Zhiqiang Yin $\left(\mathbb{D},{ }^{1}\right.$ Anying Yuan, ${ }^{4}$ \\ Ming Zhang, ${ }^{4}$ and Zhenhua Jiao ${ }^{4}$ \\ ${ }^{1}$ School of Resource and Safety Engineering, Anhui University of Science and Technology, Huainan, Anhui 232001, China \\ ${ }^{2}$ Institute of Energy, Hefei Comprehensive National Science Center, Hefei 230031, Anhui, China \\ ${ }^{3}$ Jiangsu Engineering Laboratory of Mine Earthquake Monitoring and Prevention, China University of Mining and Technology, \\ Xuzhou, Xuzhou 221116, China \\ ${ }^{4}$ State Key Laboratory of Mining-induced Response and Disaster Prevention and Control in Deep Coal Mines, \\ Anhui University of Science and Technology, Huainan, Anhui 232001, China
}

Correspondence should be addressed to Jiazhuo Li; jiazhuoli@aust.edu.cn and Zhiqiang Yin; zhqyin@aust.edu.cn

Received 28 April 2020; Revised 29 July 2020; Accepted 14 August 2020; Published 15 September 2020

Academic Editor: Richeng Liu

Copyright (c) 2020 Jiazhuo Li et al. This is an open access article distributed under the Creative Commons Attribution License, which permits unrestricted use, distribution, and reproduction in any medium, provided the original work is properly cited.

\begin{abstract}
For the quantitative recognition and characterization of the flow characteristics of polymorphism coalbed gas in tectonic coal, experiments on pore morphology, pore diameter distribution, and methane adsorption law in outburst tectonic coal were carried out by field emission scanning electron microscopy and low-field nuclear magnetic resonance. The results revealed abundant round and dense "pyrolysis pores" in outburst tectonic coals, most of which were adsorption and seepage pores, with micropores accounting for $78.2 \%$. Most pores were independent and formed the network pore space for gas enrichment and migration in outburst tectonic coal. The transverse relaxation time $\left(T_{2}\right)$ of methane adsorption in tectonic coal and crushed outburst tectonic coals presented three peaks, namely, adsorption, drifting, and free peaks. The isolation of nanopores and micropores revealed lower adsorption capacity of outburst tectonic coal than that of crushed outburst tectonic coal. The gas staged adsorption of raw coal with outburst tectonic low-permeability was observed. Under low gas pressure, the $T_{2}$ spectral peak area of methane adsorption increased remarkably, whereas that of desorbed methane increased slightly. As gas pressure was increased to a certain numerical value, the increment of methane adsorption decreased and tended to reach equilibrium. This finding reflected that methane adsorption tended to be saturated after gas pressure reached a certain value, but desorbed methane in isolated micropores increased quickly. The quantitative recognition and characterization of pore structure and gas adsorption in tectonic low-permeability outburst coal seams based on low-field magnetic resonance imaging provide an experimental method for gas exploitation in coal seams and the study and control of coal and gas outburst mechanism.
\end{abstract}

\section{Introduction}

Coal is increasingly exploited due to the exhaustion of shallow coal resources, accordingly increasing gas pressure in China [1]. Hence, the occurrence frequency, strength, and risk degree of coal and gas outburst accidents increase remarkably. In $>70 \%$ highly gassy mines in state-owned coal mines in China, 1192 coal and gas outburst mines have occurred. The absolute number of gas accidents remains high even though gas accidents decrease every year, indicating great challenges in the safety production of mines $[2,3]$.

Coal and gas outburst mechanisms vary according to different emphases on influencing factors, and the "hypothesis of comprehensive action" is widely accepted by scholars $[4,5]$. According to the statistics on abundant outburst accidents, the positions where gas outburst accidents occur and the surrounding areas are generally 
developed with tectonic coals. Almost all coal and gas outburst accidents are closely associated with tectonic coals [6]. Existing mechanical mechanisms on coal and gas outburst dynamic disasters mainly depend on the buckling theory based on energy criteria. However, strain energy, external power, and energy consumption in the buckling process of coal mass are difficult to be expressed and described by intuitive mathematical equations due to the complexity of in situ exploitation conditions, limitations of existing monitoring means, and limited availability of parameters of mathematical models. Free gas and adsorption gas coexist in coal mass. Developing methods for quantitative analysis on the storage and migration laws of free gas and adsorption gas in coal mass is important to disclose coal and gas outbursts.

In coal seam, gas flow includes three continuous processes, namely, desorption, diffusion, and seepage. Nuclear magnetic resonance (NMR) allows the determination of the distributions and connections of micropores, mesopores, macropores, and cracks in coal spaces, as well as the flow law of fluid in pores, by measuring the $T_{2}$ relaxation time of fluid [7-9]. This technique provides a new experimental strategy to study coal and gas outbursts. Yaoand Liu [10] proposed a set of relatively perfect technology for the low-field nuclear magnetism and fine quantitative characterization of shale porosity, permeability, pore type, pore structure, and methane adsorption capability. Zhou et al. [11] explored the performance of the NMR evaluation of pore structures in rock reservoirs by using the cylinder model. On the basis of an isothermal adsorption experiment, Yang et al. [12] determined the gas adsorption capacity of coal through the Langmuir model by testing the concentration, pressure, and flow rate of injected methane and $\mathrm{N}_{2}$. Wu and Sun [13] studied the methane/ $\mathrm{CO}_{2}$ mixed gas adsorption law of coal rocks under different temperatures and found that adsorption capacity was proportional to gas component concentration. Tang et al. [14] simulated the concentrated occurrence in coal-series shale gas by continuously filling in gas into the clamper with samples. Changes in adsorbed gas increment are determined by the interaction between coalseries shale and gas molecules, whereas desorbed gas increment is mainly related to the pore structure of coal-series shale. Wang et al. [15] studied shale gas and concluded that gas adsorption capacity is positively correlated with pressure but negatively correlated with temperature. Existing studies have mainly described the outburst mechanism from the macroscopic perspective or evaluated the final adsorption state of briquette from the microscopic perspective due to equipment limitations.

A compression tectonic belt is the main distribution zone of tectonic coals. Exactly 16 outburst mines are present in the Huainan Coal Mine, which lies in the North China Plate in South China. The major outburst coal seams included the No. 13-1 coal, No. 11-2 coal, and No. 8 coal of the Taiyuan Formation/Shanxi Formation [16]. In the current study, the most representative coal seam, the No. 11-2 coal of Pansan Coal Mine in Huainan City in China, was used as the research object. First, field emission scanning electron microscopy (SEM) analysis was carried out to study the porous structure of outburst tectonic coal and to reveal the network porous structure for gas accumulation and migration. Second, the pore diameter distribution of outburst tectonic coal was further concluded by the NMR technology, and pores in tectonic coal were classified. Finally, gas in micropores, small pores, mesopores, macropores, and cracks were quantitatively evaluated and characterized, revealing the response laws of gas pressure to adsorption capacity. The research conclusions provided basic data for studying the coal-gas-outburst mechanism and controlling coal-gasoutburst accidents.

\section{Experiment}

2.1. Basic Principle of the Relaxation Spectral Analysis of LowField NMR (LFNMR). The basic principle of the LFNMR technology is introduced as follows. For fluid containing ${ }^{1} \mathrm{H}$ nucleus, the spin magnetic moment of the ${ }^{1} \mathrm{H}$ nucleus may change with external magnetic field intensity, thus producing NMR measurement signals. In general, LFNMR uses transverse relaxation time $\left(T_{2}\right)$ as the characterization signal [16]. The existing state of gas in coal can generally be classified into adsorbed state and free state. In coal seams, the adsorbed and free states of gas generally account for $80 \%-90 \%$ and $10 \%-20 \%$, respectively. The NMR characteristics of ${ }^{1} \mathrm{H}$ nucleus under these two states are considerably different. The $T_{2}$ spectra of samples can be calculated from SIRT-based mathematical inversion of echo attenuation signals collected from saturated samples [17].

In magnetic field, the number of ${ }^{1} \mathrm{H}$ nucleus in gas in coal pores can be monitored by the transverse relaxation time $\left(T_{2}\right)$. For gas in coal pores, three different relaxation mechanisms occur: free relaxation, surface relaxation, and diffusion relaxation $[10,12,14]$. These relaxation mechanisms can be expressed as follows:

$$
\frac{1}{T_{2}}=\frac{1}{T_{2}^{z}}+\frac{1}{T_{2}^{b}}+\frac{1}{T_{2}^{k}}
$$

where $T_{2}$ is the transverse relaxation time of fluid in pores, which is collected by CPMG sequence. $T^{\mathbb{Z}}$ is the transverse relaxation time caused by body relaxation time. $T_{2}^{z}$ is the transverse relaxation time caused by surface transverse and by the interaction between the fluid and solid surface of pores. $T_{2}^{k}$ is the transverse relaxation time of fluid in pores caused by diffusion under magnetic field gradient.

The numerical value of $T_{2}^{z}$ generally ranges $2-3 \mathrm{~s}$, which is remarkably higher than that of $\mathrm{T}_{2}$. Therefore, $1 / T_{2}^{z}$ in equation (1) can be overlooked. This experiment was carried out in a uniform magnetic field, and the collected short-wave time was relatively short. Thus, $1 / T_{2}^{k}$ of equation (1) can also be neglected. Surface relaxation occupied the dominant effect, implying that $T_{2}$ is directly proportional to the pore diameter $[7,14]$ :

$$
\frac{1}{T_{2}} \approx \frac{1}{T_{2}^{b}}=\rho_{2}\left(\frac{S}{V}\right)=F_{s}\left(\frac{\rho_{2}}{r_{\mathrm{c}}}\right),
$$

where $\rho_{2}$ is the surface relaxation rate, $S$ is the surface area of samples, $V$ is the pore volume of samples, and $F_{\mathrm{s}}\left(F_{\mathrm{s}}=3\right.$ for 
spherical pores and $F_{\mathrm{s}}=2$ for column pores) is the geometric shape factor of coal mass $[7,18]$. Therefore, the $T_{2}$ distribution reflects the distribution of pore diameter. $T_{2}$ is positively related to the pore diameter. If a pore in the samples is a cylinder with a radius of $r$ and $\rho_{2}=10 \mu \mathrm{m} / \mathrm{s}$, the $T_{2}$ spectra could be transformed into the pore diameter distribution. Hence, the flow characteristics of methane in coal samples can be reflected by its NMR signals in $T_{2}$ spectra when the adsorbed methane and existing state of methane in coal mass are changed.

2.2. Sample Collection and Experimental Test. In this study, 60 groups of coal samples were collected from the 1611(1) panel of Pansan Coal Mine in Huainan Mining Industry Group. The average buried depth of this panel was $590 \mathrm{~m}$. The gas content and gas pressure were approximately $7.7 \mathrm{~m} / \mathrm{t}$ and 3.1 MPa. The surface coal seam has a thickness of 1.0 to $5.0 \mathrm{~m}$, an average thickness of $3.5 \mathrm{~m}$, an inclination angle of 1 to $14^{\circ}$, and an average of $6^{\circ}$. The direct roof is of silty sandstone with an average thickness of $2.7 \mathrm{~m}$; the old roof is of silty sandstone with an average thickness of $3.0 \mathrm{~m}$; the bottom plate is of dark gray mudstone with an average thickness of $2.6 \mathrm{~m}$. The newly collected coal samples were packed and rapidly carried back to the laboratory after in situ processing. The coal sample has irregular shape, medium hardness, dark black, and a small amount of texture on the surface. The samples were processed into specimens. The diameter $(\varphi)$ and height of specimens were set as 50 and $100 \mathrm{~mm}$, respectively. All specimens maintained the primary structural integrity of coal.

First, the collected coal samples were observed by SEM to determine their intuitive microstructure. Based on the microstructure of coal mass, NMR experiments under different gas pressures, confining pressures, and degrees of crushing were performed using coal structure and coalbed gas analysis and the imaging system (MacroMR-150-H-I) of Suzhou Niumai Electronic Technology Co. Ltd (Figure 1). This system was mainly composed of an NMR analysis and imaging system, high-temperature and high-pressure seepage module, adsorption-desorption module, and hightemperature- and high-pressure-resistant probe coils. The principle of the adsorption-desorption experiment is shown in Figure 2. The NMR analysis and imaging system was mainly used to analyze the micropore structure of coal samples. The online visualization of applied confining pressure and displacement pressure could be realized by the high-temperature and high-pressure seepage module. The major parameters of this analysis and imaging system mainly included a $0.3 \pm 0.05 \mathrm{~T}$ nuclear magnetism intensity of the permanent magnet, a $12.8 \mathrm{MHz}$ principal frequency of the instrument, a $60 \mathrm{~mm}$ diameter of the probe coil, a $0.15 \mathrm{~ms}$ echo interval, and a $3 \mathrm{~s}$ echo waiting time.

\subsection{Experimental Steps}

(1) Samples were prepared

(i) Raw coal samples were dried at $105^{\circ} \mathrm{C}$ for $24 \mathrm{~h}$ in an oven and then cooled for $24 \mathrm{~h}$ in vacuum. (ii) Raw coal samples were collected, and dry weight was measured.

(iii) Dry coal samples were placed in the core clamper for $T_{2}$ spectrum testing.

(iv) All pipelines were connected, and fixed confining pressures ( 10 and $8 \mathrm{MPa}$ ) were applied on the dried coal samples. In the absence of air leakage in the system for $5 \mathrm{~h}$, Step (2) must be followed.

(2) The volumes of the reference tank and sample chamber in the experimental apparatus were measured

(3) Pure methane calibration was implemented. Pure methane $(99.99 \%)$ was used as the test gas

(4) Raw coals were subjected to isothermal adsorption under different gas pressures

Coal samples were placed in the sample chamber, and gas at different pressures $(0,0.60,1.67,5.94,7.95$, and $10.20 \mathrm{MPa}$ ) was injected into the reference tank. The pressure in the reference tank $\left(P_{1}\right)$ was recorded, and the balance switch was opened. Gas in the reference tank was injected into the sample chamber, and the pressure after balance $\left(P_{2}\right)$ was recorded.

\section{Physical Properties of Low-Permeability Tectonic Coal Seam}

3.1. Pore Types. Pores in coal mass are the main areas and channels for gas accumulation and migration. The porous structure not only restricts gas content but can also affect gas control engineering, such as extraction. Genesis of structural coal: coal with structural change characteristics such as fragmentation, crumpling, and smooth surface, which is caused by the action of structural stress, and the primary structure and structure are damaged by strong cracking. Features: Apart from crushing, there are often structural mirror surface, crumpled structure (part of the original layer is reserved), crumpled mirror surface, scale-like structure, etc. Under the microscope, the directional arrangement of coal particles and microcrumpling caused by the structural flow can be seen in strongly deformed structural coal. Representative SEM images of the coal section in the Panji region are shown in Figure 3. Abundant "pyrolysis pores" have been formed in coal mass with a pore diameter that is remarkably higher than that under plutonic metamorphism. Given the collaborative effects of tectonic stress and the thermal evolution of magma, coal mass structure changed despite the degree of coal metamorphism and coal quality. As a result, the gas occurrence environment in coal mass changed, laying foundations for gas migration and local enrichment [9].

3.2. Full Pore Distribution Characteristics. Under the same detection parameters, NMR signal quantity was proportional to the flow rate of fluids containing ${ }^{1} \mathrm{H}$ nucleus in samples. A relation curve between the fluid volume and NMR signal quantity was fitted on the basis of testing a group of standard coal samples with the known hydrogen-containing fluid content (Figure 4). The measured signal quantity of the sample 


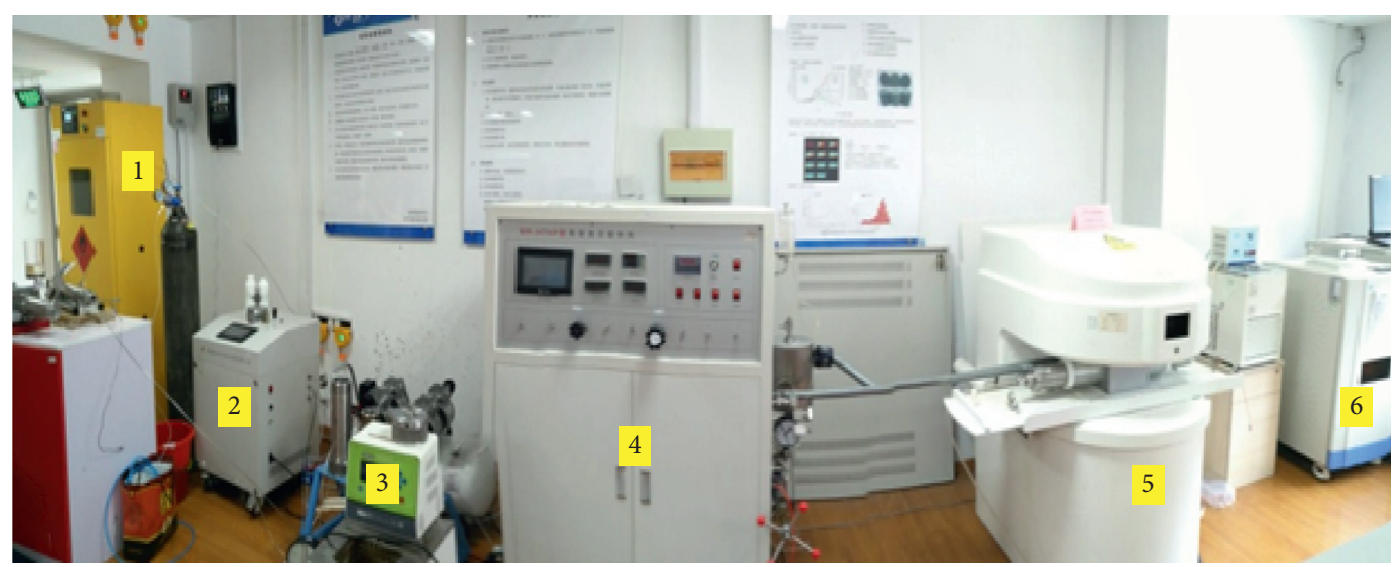

FIGURE 1: Analysis and imaging systems of coal structure and gas seepage: (1) displacement device; (2) middle container; (3) transition device, which may contain water, oil, and gas; (4) high-temperature and high-pressure system; (5) nuclear magnetism unit; and (6) closet, which mainly includes radio frequency cabinet, gradient cabinet, and imaging module.

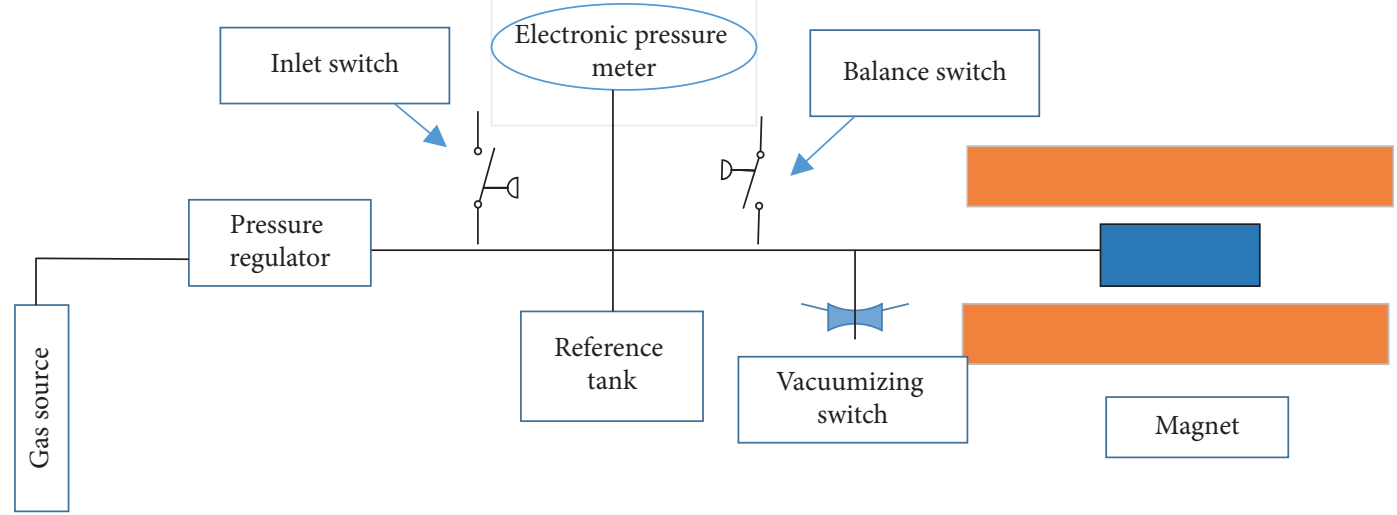

FIGURE 2: Schematic representation of adsorption-desorption experiment device.

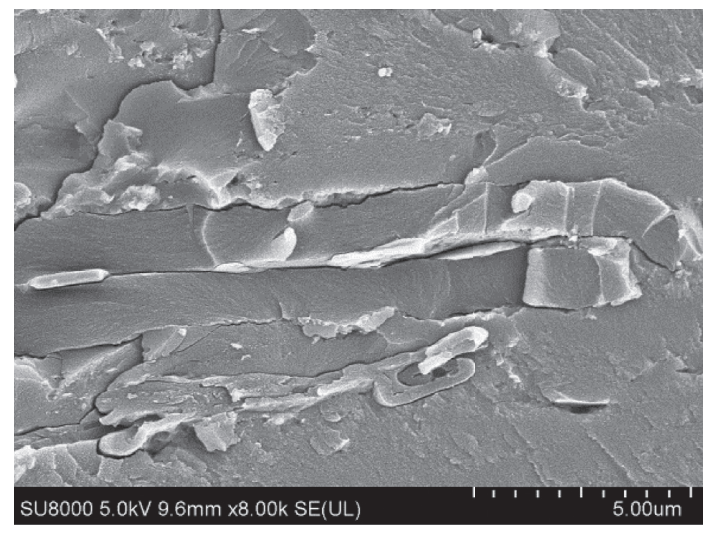

(a)

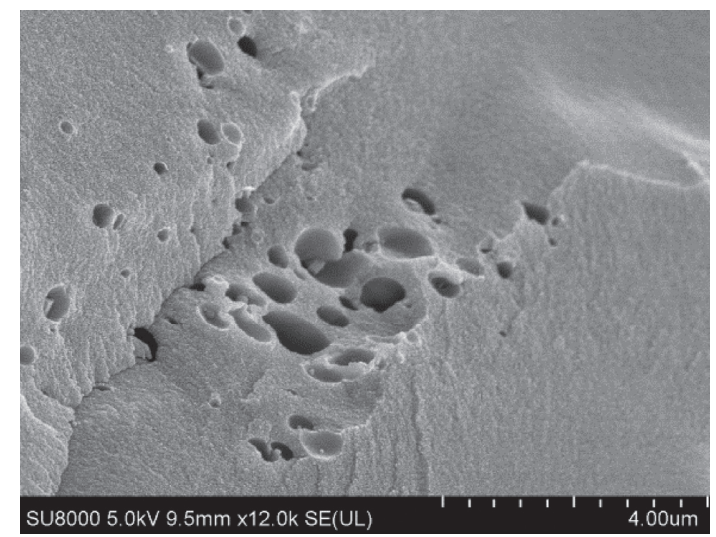

(b)

FIGURE 3: Scanning electron microscopic image of coal samples: (a) abundant microcracks (8000 of magnification time) and (b) abundant "pyrolysis pores" (12000 of magnification time).

is combined into the curve equation $(y=1345.8 x+74.685$, $\left.R^{2}=0.9998\right)$, so that the fluid content in the sample can be calculated. The porosity of raw coal is calculated by dividing the fluid volume by the sample volume.
The $T_{2}$ spectrum of the NMR of No. 1 coal sample is shown in Figure 5. The spectrum generally revealed two peaks defined as $M_{1}$ and $M_{2}$ from the left to the right of the horizontal coordinate. $M_{1}$ was the major peak, and the relaxation time 


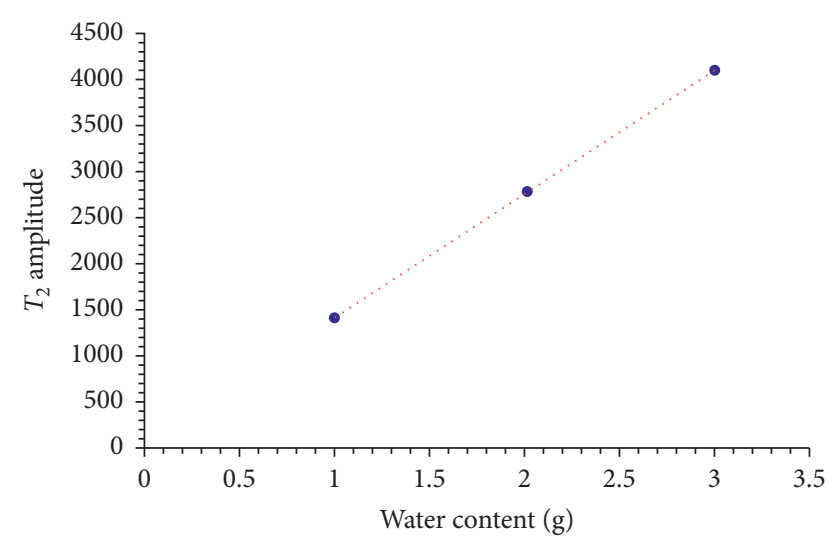

FIGURE 4: Calibration curve.

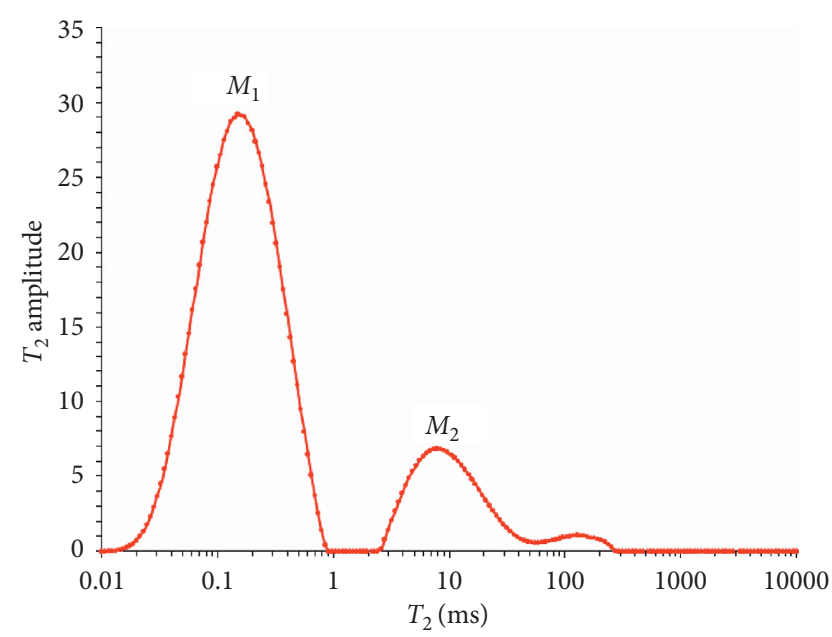

Figure 5: $T_{2}$ spectra of saturated coal samples.

ranged $0.01-1 \mathrm{~ms}$, accounting for $75 \%-95 \% . M_{2}$ mainly presented two continuous small peaks, and the relaxation time ranged 10-1000 ms. Similar laws were observed from the $T_{2}$ spectra of the NMR of other coal samples. In some coal rocks, $M_{2}$ was the single peak. The $T_{2}$ spectral distribution of coal rocks reflected the micropore structural characteristics of raw coal; that is, the pore diameter was positively correlated with $T_{2}$.

The pore radius distribution of the No. 1 coal sample is shown in Figure 6. Micropores $(<0.01 \mu \mathrm{m}$ in diameter), small pores $(0.01-0.1 \mu \mathrm{m})$, mesopores $(0.1-1 \mu \mathrm{m})$, and macropores $(1-100 \mu \mathrm{m})$ [16] all developed in coal mass. The relaxation time of the second peak of $M_{2}$ reached $1000 \mathrm{~ms}$, indicating that microcracks existed in some regions of raw coal (Figure 3(a)). The proportions of micropores, small pores, mesopores, and macropores were $78.2 \%, 6.3 \%, 13.5 \%$, and $2.0 \%$, respectively. Micropores contributed to the adsorption volume in coal mass. Small pores formed the capillary condensation and gas diffusion space. Mesopores formed the interval for the slow laminar flow of gas. Macropores formed the interval of strong laminar seepage and determined the failure surface of coal with strong failure structure. Cracks formed the interval of the mixing seepage of laminar flow and turbulent flow and determined the macro-failure surface of coal.

\section{Influencing Laws of Gas Pressure on the Gas Adsorption Characteristics of Raw Coal}

4.1. NMR Spectral Calibration of Free Gas. The variation laws of adsorbed gas and desorbed gas could be observed intuitively and quantitatively through the $T_{2}$ spectra of NMR. First, pure gas (99.99\% pure methane in the experiment) was calibrated to obtain its signal amplitudes under different gas pressures (Figure 7). On this basis, the relationship between signal amplitude and gas quality is established $(y=12836 x$, $R=0.9994$ ) (Figure 8). Subsequently, adsorbed methane mass and desorbed methane mass under different pressures were quantitatively analyzed (Table 1).

4.2. Relationship between Gas Pressure and Adsorbed Gas. The $T_{2}$ spectral distribution of coal samples measured under six adsorption balance pressures is shown in Figure 9. The $T_{2}$ spectrum presented three peaks under different adsorption pressures (0-10.2 MPa), which are distributed in intervals of 0.03-0.92, 16.8-31.4, and 95.4-3072 ms from left to right. Based on the combination of existing states of methane in the dried coal samples, the pore radius distribution in coal samples (Figure 6) and equation (2) revealed that given the small pores in coal, the specific surface area was large, the surface interaction was strong, and $T_{2}$ was short. Therefore, short relaxation time reflected methane in small pores in coals. The first, second, and third spectral peaks corresponded to the adsorbed, desorbed, and free methane in the space between coal and the clamper wall, respectively.

Methane diffused slowly from high to low concentration through small pores and micropores in the coal matrix. During the diffusion of methane, adsorption and desorption in the contacted coal pores and on the crack surface occurred simultaneously. When the signal amplitude remained constant, the seepage diffusion and adsorption-desorption processes were balanced. Figure 9 reveals that with the increase of gas pressure, the $T_{2}$ spectra of desorbed methane moved rightward gradually, and the peak area increased gradually. After a certain pressure of methane was injected into the high-pressure adsorption tank, the seepage of methane occurred in coal cracks and large pores $(>1,000 \mathrm{~nm})$ due to influences by methane pressure gradient. Only small amounts of methane was diffused and adsorbed. This finding can be explained from two aspects. First, after high-pressure gas entered into the adsorption tank, seepagestate methane was formed in cracks and large pores $(>1,000 \mathrm{~nm})$ as a response to the pressure gradient of methane. This occurrence was accompanied by methane diffusion and adsorption. Second, when the gas pressure was low, methane molecules could enter into micropores and microcracks that were larger or equal to the average molecular average free path of methane. Given the adsorption, the surface energy of methane coal on the micropores and microcracks decreased, and the surface thickness increased. Free methane also facilitated the increase of micropores and microcracks, thus resulting in the expanding deformation of coals. When methane pressure continued to increase, the 


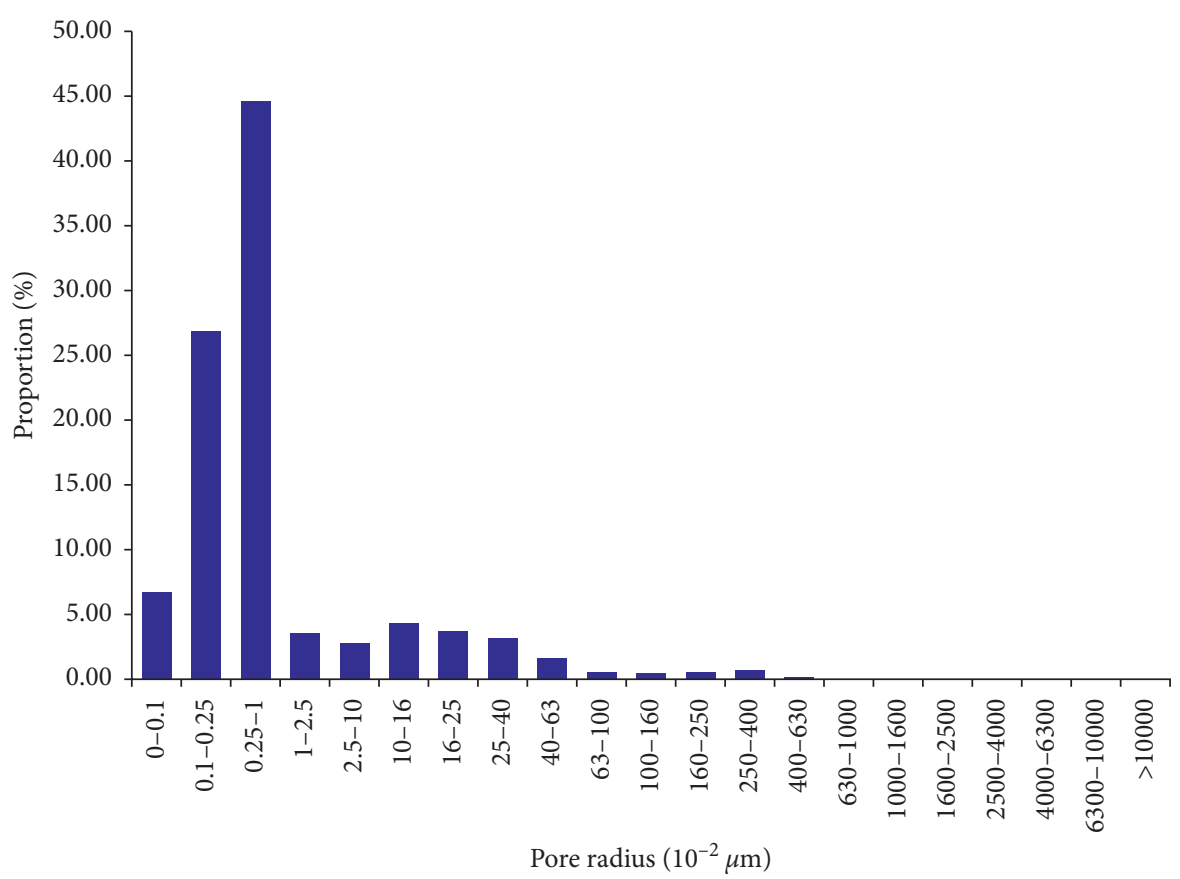

FIgure 6: Pore radius distribution of raw coal.

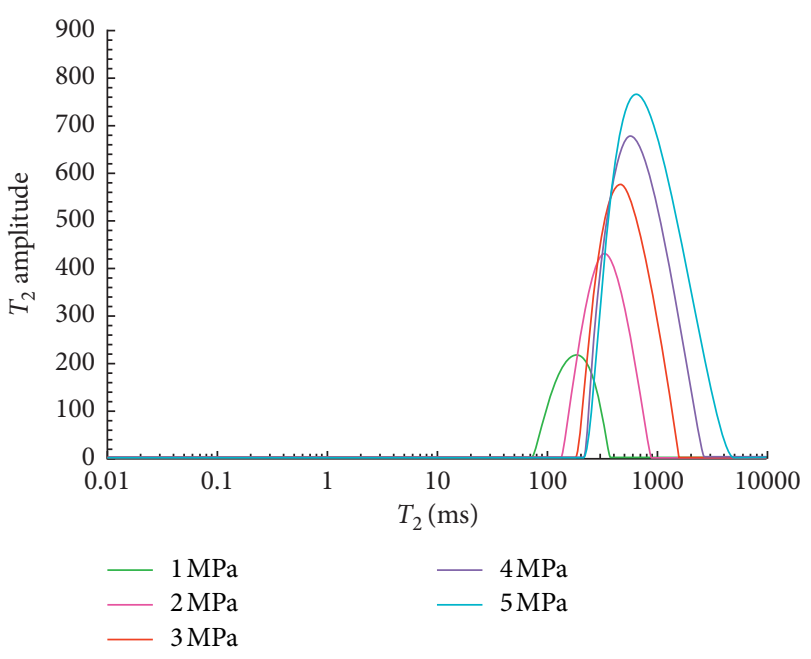

Figure 7: Signal amplitude of gas under different pressures.

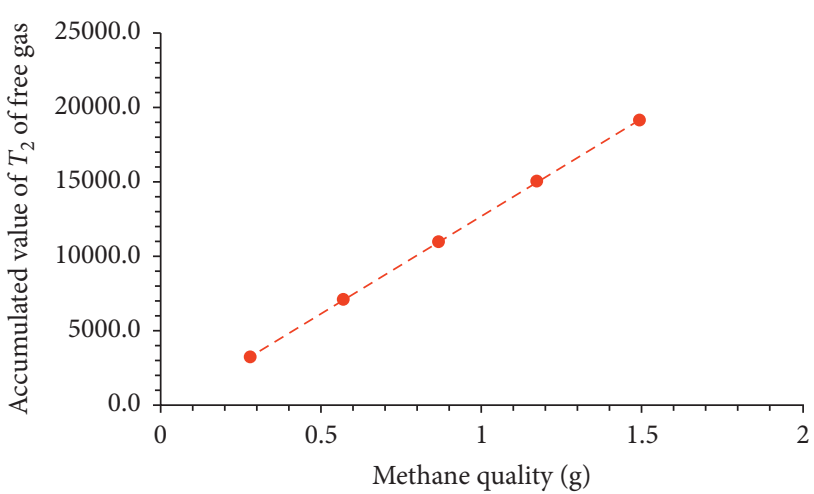

Figure 8: Calibration curve of gas quality and signal amplitude. high pressure was opened and entered into cracks larger or equal to the gas molecular scale $[19,20]$.

Coal was crushed into blocks, and $T_{2}$ spectral distribution under $0-6.32 \mathrm{MPa}$ of gas pressure was tested to further gain the adsorption law of coals under depressurized mining. The $T_{2}$ spectra of polymorphic methane in crushed coals under different pressures are shown in Figure 10. Internal surface energies were present in abundant pores in coal. At the contact of gas and internal surface, the applied force of molecules concentrated on the coal surface of gas molecules and the quantity of concentrated gas molecules increased gradually. The $T_{2}$ spectra of polymorphic methane presented three peaks from left to right, which were defined as $M_{1}, M_{2}$, and $M_{3}$. Among these peaks, $M_{1}$ (relaxation time $=0.01-1 \mathrm{~ms}$ ) was the adsorbed methane, $M_{2}$ (relaxation time $=10-130 \mathrm{~ms}$ ) reflected desorbed methane in micropores and microcracks, and $M_{3}$ (relaxation time $=130-1000 \mathrm{~ms}$ ) represented the free methane in the space between coal and clamper wall [20, 21]. A value of $0 \mathrm{MPa}$ reflected no methane entrance. For the convenient analysis of the influence of methane pressure on methane adsorption capacity, this state was used as the basement signal in testing the signals of crushed coal. When methane pressure increased from $0 \mathrm{MPa}$ to $1.01,1.46$, and $2.47 \mathrm{MPa}$, the peak area of adsorbed methane increased gradually. By contrast, the increment of desorbed methane in isolated micropores decreased, indicating that crushed coal first adsorbed methane in this stage. When the gas pressure increased continuously from $2.47 \mathrm{MPa}$ to $6.32 \mathrm{MPa}$, the increment of adsorbed methane decreased and tended to reach a balanced state. This result reflected that the adsorbed methane became increasingly saturated after methane pressure reached a certain value. Under this pressure 
TABLE 1: Relevant parameters of gas in coal samples under different gas pressures.

\begin{tabular}{lccc}
\hline Gas pressure $(\mathrm{MPa})$ & Compressibility factor & Gas quality $(\mathrm{g})$ & $T_{2}$ spectral area of desorbed gas \\
\hline 5 & 0.9175 & 1.4876 & 19208.2961 \\
4 & 0.9355 & 1.1672 & 15000.5546 \\
3 & 0.9493 & 0.8627 & 11005.3119 \\
2 & 0.9639 & 0.5664 & 7175.1711 \\
1 & 0.9828 & 0.2778 & 3295.3408 \\
\hline
\end{tabular}

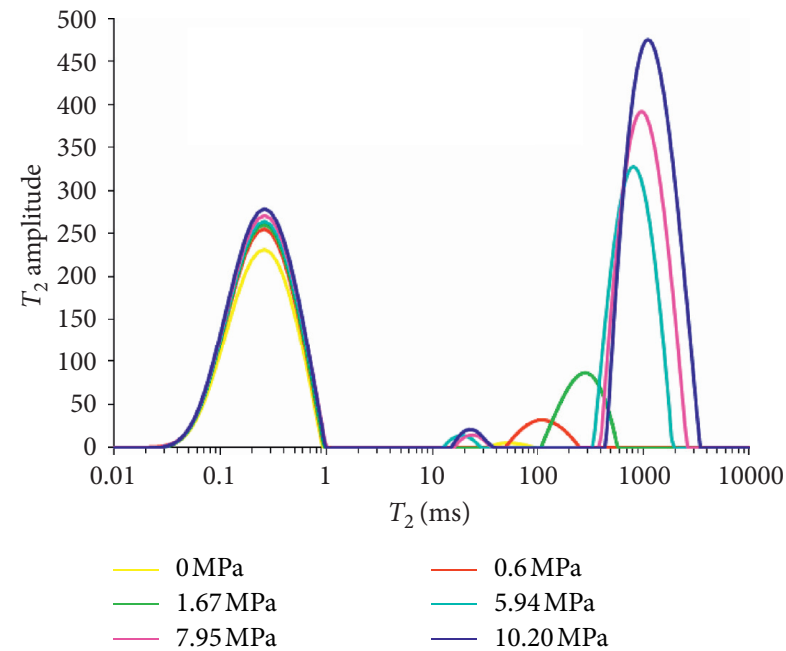

Figure 9: $T_{2}$ spectra of polymorphic methane under different pressures.

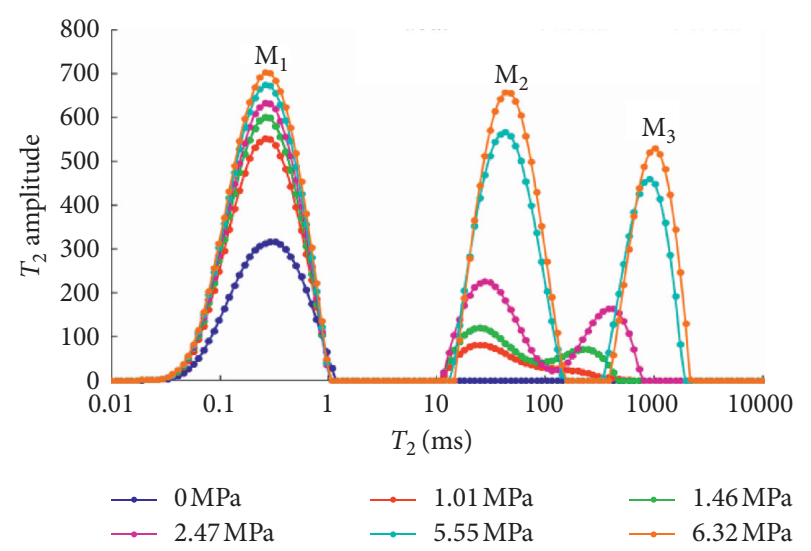

FIGURE 10: $T_{2}$ spectra of polymorphic methane in crushed coal under different pressures.

interval, desorbed methane in isolated micropores increased quickly.

The relationships between the $T_{2}$ amplitude integral and pressure of polymorphic methane are shown in Figure 11. The accumulated values of $T_{2}$ after basement removal (methane pressure $=0 \mathrm{MPa}$ ) are listed in Table 2. Comparison showed that the adsorbed methane quantity increased with the increase of gas pressure and stabilized at $5.55 \mathrm{MPa}$. Methane adsorption reached a balanced state, and the quantity of adsorbed methane stopped increasing. Desorbed

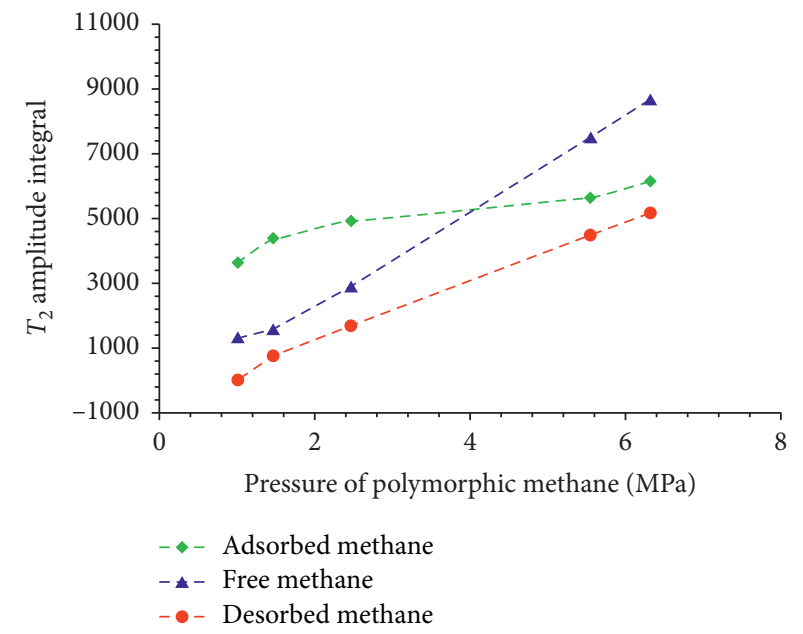

FIgURE 11: Relationship between $T_{2}$ spectra integral and gas pressure.

TABLE 2: Relationship between the quantity of polymorphic methane and gas pressures.

\begin{tabular}{lccc}
\hline $\begin{array}{l}\text { Gas pressure } \\
(\mathrm{MPa})\end{array}$ & $\begin{array}{c}\text { Peak area of } \\
M_{1}\end{array}$ & $\begin{array}{c}\text { Peak area of } \\
M_{2}\end{array}$ & $\begin{array}{c}\text { Peak area of } \\
M_{3}\end{array}$ \\
\hline 0 & 0 & 0 & 0 \\
1.01 & 3617.42 & 1340.14 & 0 \\
1.46 & 4368.66 & 1558.54 & 752.59 \\
2.47 & 4935.18 & 2878.02 & 1678.89 \\
5.55 & 5615.57 & 7542.93 & 4484.58 \\
6.32 & 6136.92 & 8692.66 & 5196.03 \\
\hline
\end{tabular}

methane in micropores also increased linearly with the increase of gas pressure.

Based on the above analysis, tectonic coal is a reservoir body with the extensive development of pores. Various pores formed by organic matters and minerals spread over the coal surface and ontology. Tectonic coals are porous solid substances with different diameter distributions. The pore size of the "pyrolysis pore" formed in coal is much larger than that formed by plutonic metamorphism, and the shape of the pore also changes, showing a "hemispherical shape," the pore size gradually decreases from outside to inside, and the edge is smoother. Mostpores were round and seepage pores and with dense adsorption, and most pores were isolated rather than connected. The connected nano-micro base pores and cracks formed the seepage channel of gas together [22], and the size of seepage channel directly determined the 
permeability of coals $[23,24]$, thus influencing the extraction effect of surface boreholes and underground boreholes.

\section{Conclusions}

Low-field NMR technology allows the fast and extensive acquisition of big data. The processing of high-temperature and high-pressure NMR probe and gas adsorption-desorption in coal seams provides a new experimental method for the quantitative evaluation of pore diameter distribution and gas flow state in coal seams.

Abundant round and dense "pyrolysis pores" were present in coals. Most pores were isolated rather than connected, most of which were adsorption and seepage pores. Abundant microcracks were also present. These pyrolysis pores and microcracks formed the network space for gas enrichment and migration in coal. The $T_{2}$ spectra of methane in raw coal and crushed coal exhibited three peaks, namely, adsorption, drifting, and free peaks. The isolation of nanopores and micropores revealed that the gas adsorption capacity of raw materials was lower than that of crushed coal.

Under low gas pressure, the $T_{2}$ spectral peak area of adsorbed methane increased quickly with the increase of methane pressure, whereas the desorbed methane in isolated micropores increased slightly. As gas pressure increased up to a certain value, the increment of adsorbed methane decreased and became increasingly balanced. This result indicates that the adsorbed methane became increasingly saturated after methane pressure reached a certain value, but desorbed methane in isolated micropores increased quickly.

\section{Data Availability}

All data included in this study are available upon request to the corresponding author.

\section{Conflicts of Interest}

The authors declare that there are no conflicts of interest regarding the publication of this paper.

\section{Acknowledgments}

This research was supported by the Anhui Provincial Natural Science Foundation (Nos. 1808085QE177, 1908085QE183, 1908085QE184, and 1908085QE186), the National Key R\&D Program of China (No. 2017YFC0804202), and the National Natural Science Foundation of China (No. 51874006).

\section{References}

[1] G. Yin, X. Li, J. Lu, and M. Li, "Disaster-causing mechanism of compound dynamic disaster in deep mining under static and dynamic load conditions," Meitan Xuebao/Journal of the China Coal Society, vol. 42, no. 9, pp. 2316-2326, 2017.

[2] M. Qian, J. Xu, and J. Wang, "Further on the sustainable mining of coal," Journal of China Coal Society, vol. 42, no. 9, pp. 2316-2326, 2018.

[3] J. Wang, H. Kang, J. Liu et al., "Layout strategic research of green coal resource development in China," Journal of China
University of Mining and Technology, vol. 47, no. 1, pp. 15-20, 2018.

[4] M. Luo, C. Fan, S. Li et al., "Failure criteria of the geological dynamic system of coal and gas outburst," Zhongguo Kuangye Daxue Xuebao/Journal of China University of Mining and Technology, vol. 47, no. 1, pp. 137-144, 2018.

[5] Y. Pan, "Integrated study on compound dynamic disaster of coal-gas outburst and rockburst," Journal of China Coal Society, vol. 47, no. 1, pp. 105-112, 2016.

[6] Y. Zhang, Z. Zhang, and Y. Cao, "Deformed-coal structure and control to coal-gas outburst," Journal of China Coal Society, vol. 32, no. 3, pp. 281-284, 2007.

[7] Y. Cai, D. Liu, Y. Yao, J. Li, and G. Zheng, "The evolution of petrophysical properties of coalbed methane reservoirs under the heat treatment," Earth Science Frontiers, vol. 21, no. 1, pp. 240-248, 2014.

[8] R. Xie, L. Xiao, and S. Fu, "Temperature effect of NMR surface relaxation in water saturated rocks," Journal of China University of Petroleum, vol. 32, no. 2, pp. 45-52, 2008.

[9] S. Xie, Y. Yao, J. Chen, and W. Yao, "Research of micro-pore structure in coal reservoir using low-field nmr," Meitan Xuebao/Journal of the China Coal Society, vol. 40, no. 1, pp. 170-176, 2015.

[10] Y. Yao and D. Liu, "Petrophysical properties and fluids transportation in gas shale: a NMR relaxation spectrum analysis method," Journal of China Coal Society, vol. 43, no. 1, pp. 181-189, 2018.

[11] C. Zhou, T. Liu, Z. Ma, Z. Liu, and G. Liu, "Evaluation of pore structure using sphere-cylinder model," Acta Petrolei Sinica, vol. 27, no. 1, pp. 92-96, 2006.

[12] H. Yang, Z. Feng, and L. Chen, "Analysis of replacementdisplacement effect and its change mechanism in simulation experiment of nitrogen injection into coal seam," Journal of China Coal Society, vol. 41, no. 9, pp. 2246-2250, 2016.

[13] D. Wu and K. Sun, "Experimental study for coal briquette adsorption of $\mathrm{CH}_{4} / \mathrm{CO}_{2}$ mixture under different temperatures," Chinese Journal of Rock Mechanics and Engineering, vol. 32, no. 2, pp. 3291-3296, 2013.

[14] J. Tang, H. Tian, N. Yu, and J. Ding, "Experimental study of influence of gas pressure on coal shale gas adsorption characteristics based on nuclear magnetic resonance spectrum," Rock and Soil Mechanics, vol. 37, no. 2, pp. 203-208, 2016.

[15] F. Wang, Z. He, X. Meng, L. Bao, and H. Zhang, "Occurrence of shale gas and prediction of original gas in-place (OGIP)," Natural Gas Geoscience, vol. 22, no. 3, pp. 501-510, 2011.

[16] Q. Shao, E. Wang, H. Wang, Q. Yin, and F. Li, "Control to coal and gas outburst of tectonic coal distribution," Meitan Xuebao/Journal of the China Coal Society, vol. 35, no. 2, pp. 250-254, 2010.

[17] S. Li, M. Luo, C. Fan, H. Bi, and Y. Ren, "Quantitative characterization of the effect of acidification in coals by $\mathrm{nmr}$ and low-temperature nitrogen adsorption," Journal of China Coal Society, vol. 42, no. 7, pp. 1748-1756, 2017.

[18] X. Wang, Z. Yang, H. LI, and H. Guo, "Experimental study on pore structure of low permeability core with NMR spectra," Journal of South West Petroleum University (Science and Technology Edition), vol. 32, no. 2, pp. 69-72, 2010.

[19] X. He, E. Wang, and H. Lin, "Coal deformation and fracture mechanism under pore gas action," Journal of China University of Mining Technology, vol. 25, no. 1, pp. 6-11, 1996.

[20] Y. Liu, S. Cao, Y. Li, J. Wang, and Y. Bai, "Experimental study of swelling deformation effect of coal induced by gas adsorption," Yanshilixue Yu Gongcheng Xuebao/Chinese Journal 
of Rock Mechanics and Engineering, vol. 29, no. 12, pp. 2484-2491, 2010.

[21] K. Peng, J. Zhou, Q. Zou, J. Zhang, and F. Wu, "Effects of stress lower limit during cyclic loading and unloading on deformation characteristics of sandstones," Construction and Building Materials, vol. 217, no. 7, pp. 202-215, 2019.

[22] G. Xie, Z. Yin, L. Wang, Z. Hu, and C. Zhu, "Effects of gas pressure on the failure characteristics of coal," Rock Mechanics and Rock Engineering, vol. 50, no. 7, pp. 1711-1723, 2017.

[23] Z. Yin, Z. Hu, and Z. Wei, "Assessment of blasting-induced ground vibration in an open-pit mine under different rock properties," Advances in Civil Engineering, vol. 1, no. 10, 2018.

[24] Z. Yin, W. Chen, H. Hao et al., "Dynamic compressive test of gas-containing coal using a modified split Hopkinson pressure bar system," Rock Mechanics and Rock Engineering, vol. 53, no. 2, pp. 815-829, 2020. 